\title{
Incidence of elevated lipoprotein (a) levels in a large cohort of patients with cardiovascular disease
}

\author{
Frank van Buuren ${ }^{1}$ Dieter Horstkotte ${ }^{1}$ Cornelius Knabbe ${ }^{2}$ Dennis Hinse ${ }^{2} \cdot$ Klaus Peter Mellwig$^{1}$
}

Published online: 22 February 2017

(c) The Author(s) 2017. This article is available at SpringerLink with Open Access.

\begin{abstract}
Background Recently it has been demonstrated that elevated lipoprotein (a) (LPA) levels are associated with an increased risk of cardiovascular disease across multiple ethnic groups. However, there is only scanty data about the incidence of elevated LPA levels in different patient cohorts. As a consequence, we aimed to examine whether patients with elevated LPA levels might be seen more often in a cardiovascular center in comparison to the general population. Methods We reviewed LPA concentrations of 52,898 consecutive patients who were admitted to our hospital between January 2004 and December 2014. We subdivided them into different groups according to their LPA levels. Data was compared to available information in medical literature.

Results $26.4 \%$ of the patients had LPA levels $>30 \mathrm{mg} / \mathrm{dl}$ which is in line with the data from literature. Mean level of LPA concentration in our study was twice as high in comparison to the general population ( $25.8 \%$ vs. $13.3 \%) .4 .6 \%$ had LPA levels $>98 \mathrm{mg} / \mathrm{dl}$ (general population $<0.3 \%$ ).

Conclusion In patients admitted to a cardiovascular center the proportion of LPA $>30 \mathrm{mg} / \mathrm{dl}$ is comparable to the general population but mean levels over all are twice as high and the proportion of patients with LPA levels of $>98 \mathrm{mg} / \mathrm{dl}$ is extremely higher.
\end{abstract}

This article is part of the special issue "Lp(a) - the underestimated cardiovascular risk factor".

Frank van Buuren

fvbuuren@hdz-nrw.de

1 Clinic for Cardiology, Herz- und Diabeteszentrum NRW, Ruhr-Universität Bochum, Georgstr. 11, 32545 Bad Oeynhausen, Germany

2 Insitute for Laboratory and Transfusion Medicine, Herz- und Diabeteszentrum NRW, Ruhr-Universität Bochum, Bad Oeynhausen, Germany
Keywords Lipoprotein (a) - Cholesterol · Cardiovascular disease $\cdot$ Epidemiology $\cdot$ Risk stratifcation

\section{Background}

Total cholesterol, high density lipoprotein (HDL), and low density lipoprotein (LDL) are frequently used to assess the risk of atherosclerosis due to dyslipidemia [1]. In recent years it came evident that lipoprotein (a) (LPA) as well is supposed to play an important role in the genesis of atherosclerosis and thrombosis.

LPA is composed of an LDL-like particle in which apolipoprotein B100 is covalently attached to apolipoprotein (a) by a disulfide bond [2, 3]. Plasma levels of LPA are genetically determined by variation in the LPA gene coding for apolipoprotein (a) [4]. Apolipoprotein (a) has high structural resemblance to plasminogen [5]. Hence, due to its composition, Erqou concluded in a meta-analysis that there is a continuous, independent association of LPA and the risk of coronary heart disease [6]. Furthermore, epidemiological data suggest that elevated LPA levels are pro-atherogenic while the exact molecular mechanism by which LPA contributes to the atherosclerotic process remains unclear [4, 7-10].

The incidence of LPA levels $>30 \mathrm{mg} / \mathrm{dl}$ is supposed to be between 7 and $26 \%$ in a general European population [1, 11-13]. LPA levels $>30 \mathrm{mg} / \mathrm{dl}$ are proved to be independently associated with a three-fold risk of major adverse cardiovascular events in patients after coronary artery bypass grafting [3]. Other diseases like thromboembolism and chronic heart failure due to impaired left ventricular function are currently evaluated in larger patient groups [8]. Aortic valve stenosis (AVS) is a valvular heart disease of increasing interest as its prevalence rises with age 
Table 1 Laboratory findings in 52,898 patients. Subdivision according to their LPA levels and number of individuals in the different LPA-groups with $\mathrm{LDL}>130 \mathrm{mg} / \mathrm{dl}, \mathrm{HDL}<40 \mathrm{mg} / \mathrm{dl}, \mathrm{HbAlc}>6.4 \%$ or creatinine $>1.29 \mathrm{mg} / \mathrm{dl}$

\begin{tabular}{|c|c|c|c|c|c|c|c|c|c|c|}
\hline $\mathrm{LPA}$ & & & LDL & & HDL & & $\mathrm{HbA1c}$ & & Crea & \\
\hline $\mathrm{mg} / \mathrm{dl}$ & $n$ & $\%$ & $\begin{array}{l}n \\
>130 \mathrm{mg} / \mathrm{dl}\end{array}$ & $\%$ & $\begin{array}{l}n \\
<40 \mathrm{mg} / \mathrm{dl}\end{array}$ & $\%$ & $\begin{array}{l}n \\
>6.4 \%\end{array}$ & $\%$ & $\begin{array}{l}n \\
>1.29 \mathrm{mg} / \mathrm{dl}\end{array}$ & $\%$ \\
\hline$<180$ & 206 & 0.39 & 107 & 51.94 & 36 & 17.48 & 68 & 33.01 & 43 & 20.87 \\
\hline $151-180$ & 379 & 0.72 & 173 & 45.65 & 76 & 20.05 & 125 & 32.98 & 97 & 25.59 \\
\hline $121-150$ & 771 & 1.46 & 345 & 44.75 & 179 & 23.22 & 236 & 30.61 & 181 & 23.48 \\
\hline $91-120$ & 1635 & 3.09 & 696 & 42.57 & 365 & 22.32 & 535 & 32.72 & 315 & 19.27 \\
\hline $61-90$ & 4934 & 9.33 & 1930 & 39.12 & 1124 & 22.78 & 1930 & 39.12 & 932 & 18.89 \\
\hline $31-60$ & 6144 & 11.61 & 2219 & 36.12 & 1741 & 28.34 & 2180 & 35.48 & 1209 & 19.68 \\
\hline $0-30$ & 38,829 & 73.40 & 13127 & 33.81 & 10280 & 26.48 & 14741 & 37.96 & 6993 & 18.01 \\
\hline
\end{tabular}

LPA lipoprotein (a), LDL low density lipoprotein, $H D L$ high density lipoprotein, $H b A l c$ glycated hemoglobin, Crea creatinine

and is estimated to affect up to $2-7 \%$ of all individuals aged $>65$ years $[14,15]$. The identification of risk factors for valvular calcifications and AVS is of utmost interest as the burden of AVS is high and often ends up in surgical or catheter-based treatment like transcatheter aortic valve implantation (TAVI) $[14,16]$. In the last years it became evident that AVS progression shares risk factors with atherosclerosis. There are also hints that elevated LPA levels contribute to an increased incidence of AVS [8]. In addition, very recent studies report on a relationship between mitral valve stenosis and elevated LPA levels in patients with coexisting peripheral arterial disease [17].

Next to cardiac manifestations it could be demonstrated that elevated LPA levels are associated with extracardiac arteriosclerosis like peripheral arterial disease and stenosis of the arteria carotis [18, 19]. Von Depka reports about elevated LPA levels as an independent risk factor for venous thromboembolism [11]. Furthermore, it has been hypothesized that LPA contributes to initial wound healing but inhibits external fibrinolysis in a later phase of the healing process leading to its corresponding problems [20]. Moreover, a higher risk for abortions was reported in patients with elevated LPA levels [13].

In summary, elevated LPA levels seem to predispose for numerous non-cardiovascular and cardiovascular diseases and all these studies thrust LPA into the limelight as it appears to play an important role in various processes [21]. However, there is only rare data about the dispersion of elevated LPA levels in different patient communities.

As a consequence, we aimed to examine whether patients with elevated LPA levels might be seen more often in a cohort with cardiovascular disease in comparison to a normal population.

\section{Patients and methods}

In a total of 52,898 consecutive patients $(37.81 \%$ females, age $61.08 \pm 11.03$ years) admitted to our Center between January 2004 and December 2014 we analyzed their full lipid profile including LPA, triglycerides, total cholesterol, HDL, and LDL. Furthermore, we checked for diabetes mellitus (glycated hemoglobin $=\mathrm{HbA} 1 \mathrm{c}$ ) and renal function (creatinine, glomerular filtration rate (GFR)). Patients were assigned to seven different groups according to their LPA concentrations $(30 \mathrm{mg} / \mathrm{dl}$ steps and more than $180 \mathrm{mg} / \mathrm{dl})$.

Table 1 shows the distribution of LPA concentrations in the different groups.

\section{Results}

$32.9 \%$ out of 52,898 patients had LPA levels of $>20 \mathrm{mg} / \mathrm{dl}$ ( $26.6 \%>30 \mathrm{mg} / \mathrm{dl}$ and $18.4 \%>50 \mathrm{mg} / \mathrm{dl}$ correspondingly). There was no difference in the groups according $\mathrm{HbA} 1 \mathrm{c}$ levels and renal function (creatinine).

\section{Discussion}

The last three decades have seen favorable trends in LDL hypercholesterolemia most likely due to an increased awareness in the context of cardiovascular disease and the extended use of lipid-lowering drugs [22]. It was demonstrated that increased circulating levels of LPA are associated with an increased risk ofcardiovascular disease (coronary heart disease, aortic valve stenosis etc.) and stroke [23].

A substantial fraction of the general population has LPA concentrations that might place them at increased risk for cardiovascular disease [21]. Unfortunately there is only scanty data about the incidence of increased LPA levels 
in the general population and, even more interesting, in populations with cardiovascular disease [7].

\section{Proportion of different elevated LPA levels in the general population}

Plasma levels of LPA are similar in men and women. Epidemiological studies showed that LPA concentrations are lowest in non-Hispanic Caucasians (median $12 \mathrm{mg} / \mathrm{dl}$ ), Chinese (median $11 \mathrm{mg} / \mathrm{dl}$ ), and Japanese (median 13) [24, 25]. On the other hand, they are supposed to be slightly higher in Hispanics (median 19), and even higher levels can be seen in individuals of African origin (median 39).

The typical distributions of LPA in the general Caucasian population can be derived from the Copenhagen City Heart Study, in which more than 20,000 individuals were included. In a subgroup analysis with 3000 men and 3000 women they found that $20 \%$ had LPA plasma levels $>50 \mathrm{mg} / \mathrm{dl}$ representing individuals above the 80th percentile [24]. This data is in line with our findings, where $18.4 \%$ of our individuals turned out to have LPA levels $>50 \mathrm{mg} / \mathrm{dl}$.

Other surveys report about the incidence of LPA levels $>30 \mathrm{mg} / \mathrm{dl}$ in a general adult population in Italy [12]. In that analysis 1195 individuals were screened and about $26 \%$ of them had levels $>30 \mathrm{mg} / \mathrm{dl}$. This correlates to the proportion of patients in our group in which $26.6 \%$ showed corresponding levels. Bucci reports about LPA levels $>20 \mathrm{mg} / \mathrm{dl}$ in about $25 \%$ of a general population of Caucasian origin [26]. In contrast, $32.9 \%$ of our patient cohort had LPA levels $>20 \mathrm{mg} / \mathrm{dl}$ indicating that elevated levels might predispose for admission in a cardiovascular center.

\section{Mean levels of LPA in different communities}

In terms of mean LPA levels the results are markedly different. However, the comparison to available data in literature is difficult as our study includes patients with cardiovascular disease and not members of a general population.

Hopewell investigated the impact of elevated LPA levels on coronary heart disease and compared his findings with the LPA levels of a control group which was supposed to be healthy [27]. Mean age in this group was 60.9 years, mean LPA levels in the healthy individuals were $10.56 \mathrm{mg} / \mathrm{dl}$. In a general population study, Langsted found mean LPA levels of $17.3 \mathrm{mg} / \mathrm{dl}$ [28] compared tos $13.3 \mathrm{mg} / \mathrm{dl}$ in a survey performed by Bucci [26]. In contrast, mean levels were twice as high in our patient collective $(25.8 \mathrm{mg} / \mathrm{dl})$. This might support the hypothesis that elevated LPA levels can predispose for cardiovascular diseases.

\section{Extremely elevated LPA levels}

The highest levels of LPA in the different general population groups were between 98 and $217 \mathrm{mg} / \mathrm{dl}$ [26, 29]. However, these extreme concentrations were rare and in none of the surveys higher than $1 \%$. Our population included 2415 individuals (4.6\%) with levels $>98 \mathrm{mg} / \mathrm{dl}$ and 586 with levels $>150 \mathrm{mg} / \mathrm{dl}(1.1 \%)$. These findings suggest that patients who were admitted to a cardiovascular center more often have extremely high levels of LPA.

Up to now we cannot provide the exact diagnosis of the patients with extreme LPA levels as this is still subject of an ongoing analysis.

\section{Treatment options}

Up to now elevated LPA concentrations are largely resistant to therapeutic interventions like drug therapy or diet and thus the appropriate strategy in terms of acceptable LPA levels and coexisting risk factors has been discussed extensively. Due to their genetic disposition, LPA levels are intraindividually stable over time.

Niacin has a potential to decrease plasma LPA levels by approximately $20-30 \%$ [21]. However, it was withdrawn from the market due to major side effects, mainly hepatotoxicity and flushing.. Furthermore, two recent clinical trials found that, despite positive effects on LPA plasma levels, niacin failed to improve clinical outcome endpoints [30]. In particular there is no data that describes the influence of niacin therapy on LPA levels in a large community.

Alternatively, newly developed drugs like mipomersin, a second generation antisense oligonucleotide, reduces plasma levels of LPA by 21-36\% [31]. Moreover, PCSK9inhibitors, drugs that affect LPA levels by influencing the LDL-receptor degradation, may reduce LPA levels by up to $30 \%$. However, neither for this therapeutic option there are still no data available illuminating clinical endpoints [32].

Currently, only LPA apheresis is a proved therapy to reduce LPA levels by more than $60 \%$ per session thus having a positive influence on the reduction of cardiovascular events [33-37].

\section{Conclusion}

The presented data shows, as far as we know, for the first time the incidence of elevated LPA concentrations in a large cohort of patients in a cardiovascular center. Mean LPA concentrations are higher and extreme LPA values are seen more often in cardiovascular patients whereas the proportion of individuals with levels $>30 / \mathrm{mg}$ is similar in comparison to the general population. Against this background 
the crucial questions of correct cut-off values and the new therapeutic options beyond apheresis therapy have to be addressed in the upcoming years.

\section{Limitations of the study}

The study was not designed as a population-based study because all patients are individuals who were admitted to a cardiovascular center. Many of them were diagnosed to suffer from cardiac disease. However, the proportion of patient in whom no relevant cardiovascular disease was found is unknown and is still subject of ongoing analysis.

Conflict of interest F. van Buuren received honoraria for lectures from Daiichi Sankyo, Amgen and Fresenius Medical Care and travel reimbursement from Biotronik. K.P. Mellwig received honoraria for lectures and travel reimbursement from B. Braun and Fresenius Medical Care. D. Horstkotte, C. Knabbe and D. Hinse declare that they have no competing interests.

Open Access This article is distributed under the terms of the Creative Commons Attribution 4.0 International License (http:// creativecommons.org/licenses/by/4.0/), which permits unrestricted use, distribution, and reproduction in any medium, provided you give appropriate credit to the original author(s) and the source, provide a link to the Creative Commons license, and indicate if changes were made.

\section{References}

1. Scheidt-Nave C, Du Y, Knopf H, Schienkiewitz A, Ziese T, Nowossadeck E, Goesswald A, Busch MA (2013) Prevalence of dyslipidimia among adults in Germany. Bundesgesundheitsblatt 56:661-667

2. Berg K (1963) A new serum type system in man - the LP system. Acta Pathol Microbiol Scand 59:369-382

3. Ezhov MV, Safarova MS, Afanasieva OI, Kukharchuk VV, Pokrovsky SN (2014) Lipoprotein(a) level and apolipoprotein(a) phenotype as predictors of long-term cardiovascular outcomes after coronary artery bypass grafting. Atherosclerosis 235:477-482

4. Kamstrup PR, Tybjærg-Hansen A, Nordestgaard BG (2013) Extreme lipoprotein(a) levels and improved cardiovascular risk prediction. J Am Coll Cardiol 61:1146-1156

5. McLean JW, Tomlinson JE, Kuang WJ, Eaton DL, Chen EY, Fless GM, Scanu AM, Lawn RM (1987) cDNA sequence of human apolipoprotein(a) is homologous to plasminogen. Nature 330:132-137

6. Erqou S, Kaptoge S, Perry PL, Di Angelantonio E, Thompson A, White IR, Marcovina SM, Collins R, Thompson SG, Danesh J (2009) Lipoprotein(a) concentration and the risk of coronary heart disease, stroke, and nonvascular mortality. JAMA 302:412-423

7. Graham MJ, Viney N, Crooke RM, Tsimikas S (2016) Antisense inhibition of apolipoprotein (a) to lower plasma lipoprotein (a) levels in humans. J Lipid Res 57:340-351

8. Nordestgaard BG, Langsted A (2016) Lipoprotein (a) as a cause of cardiovascular disease: insights from epidemiology, genetics, and biology. J Lipid Res 57:1953-1975

9. Kamstrup PR, Benn M, Tybjaerg-Hansen A, Nordestgaard BG (2008) Extreme lipoprotein(a) levels and risk of myocardial infarction in the general population: the Copenhagen City Heart Study. Circulation 117:176-184
10. Schatton CM (2015) Lp(a) als unabhängiger Risikofaktor für eine KHK - Eine Mached-Pair-Analyse aus 32.000 Laboruntersuchungen. Dissertation, Ruhr University Bochum, Germany.

11. von Depka M, Nowak-Göttl U, Eisert R, Dieterich C, Barthels M, Scharrer I, Ganser A, Ehrenforth S (2000) Increased lipoprotein (a) levels as an independent risk factor for venous thromboembolism. Blood 96:3364-3368

12. Lippi G, Targher G, Franchini M, Guidi GC (2009) Biochemical correlates of lipoprotein(a) in a general adult population. Possible implications for cardiovascular risk assessment. J Thromb Thrombolysis $27: 44-47$

13. Weidensee S, Demuth S, Schleußner E (2012) Häufigkeit von erhöhten Lipoprotein(a)-Spiegeln in einem ausgewählten Patientenkollektiv mit habituellen Aborten und Spätaborten. Z Geburtshilfe Neonatol 216:P37. doi:10.1055/s-0032-1309129

14. Arsenault BJ, Boekholdt SM, Dubé MP, Rhéaume E, Wareham NJ, Khaw KT, Sandhu MS, Tardif JC (2014) Lipoprotein(a) levels, genotype, and incident aortic valve stenosis: a prospective mendelian randomization study and replication in a case-control cohort. Circ Cardiovasc Genet 7:304-310

15. Hung MY, Witztum JL, Tsimikas S (2014) New therapeutic targets for calcific aortic valve stenosis: the lipoprotein(a)-lipoprotein-associated phospholipase A2-oxidized phospholipid axis. J Am Coll Cardiol 63:478-480

16. Gotoh T, Kuroda T, Yamasawa M, Nishinaga M, Mitsuhashi T, Seino Y, Nagoh N, Kayaba K, Yamada S, Matsuo H et al (1995) Correlation between lipoprotein(a) and aortic valve sclerosis assessed by echocardiography (the JMS Cardiac Echo and Cohort Study). Am J Cardiol 76:928-932

17. Hojo Y, Kumakura H, Kanai H, Iwasaki T, Ichikawa S, Kurabayashi M (2016) Lipoprotein(a) is a risk factor for aortic and mitral valvular stenosis in peripheral arterial disease. Eur Heart J Cardiovasc Imaging 17:492-497

18. van Buuren F, Sommer JA, Kottmann T, Horstkotte D, Mellwig KP (2015) Extracardiac manifestation of elevated lipoprotein(a) levels - cumulative incidence of peripheral arterial disease and stenosis of the carotid artery. Clin Res Cardiol Suppl 10:39-45

19. Imhof A, Rothenbacher D, Khuseyinova N, Hoffmeister A, Maerz W, Nauck M, Scharnagl H, Koenig W, Brenner H (2003) Plasma lipoprotein $\mathrm{Lp}(\mathrm{a})$, markers of haemostasis and inflammation, and risk and severity of coronary heart disease. Eur J Cardiovasc Prev Rehabil 10:362-370

20. Yano Y, Shimokawa K, Okada Y, Noma A (1997) Immunolocalization of lipoprotein(a) in wounded tissues. J Histochem Cytochem 45:559-568

21. Boffa MB, Koschinsky ML (2013) Screening for and management of elevated Lp(a). Curr Cardiol Rep 15:417

22. Cohen JD, Cziraky MJ, Cai Q, Wallace A, Wasser T, Crouse JR, Jacobson TA (2010) 30-year trends in serum lipids among United States adults: results from the National Health and Nutrition Examination Surveys II, III, and 1999-2006. Am J Cardiol 106:969-975

23. Gurdasani D, Sjouke B, Tsimikas S, Hovingh GK, Luben RN, Wainwright NW, Pomilla C, Wareham NJ, Khaw KT, Boekholdt SM, Sandhu MS (2012) Lipoprotein(a) and risk of coronary, cerebrovascular, and peripheral artery disease: the EPIC-Norfolk prospective population study. Arterioscler Thromb Vasc Biol 32:3058-3065

24. Nordestgaard BG, Chapman MJ, Ray K, Borén J, Andreotti F, Watts GF, Ginsberg H, Amarenco P, Catapano A, Descamps OS, Fisher E, Kovanen PT, Kuivenhoven JA, Lesnik P, Masana L, Reiner Z, Taskinen MR, Tokgözoglu L, Tybjærg-Hansen A (2010) European Atherosclerosis Society Consensus Panel. Lipoprotein(a) as a cardiovascular risk factor: current status. Eur Heart J 31:2844-2853

25. Forbang NI, Criqui MH, Allison MA, Ix JH, Steffen BT, Cushman M, Tsai MY (2016) Sex and ethnic differences in the associations 
between lipoprotein(a) and peripheral arterial disease in the MultiEthnic Study of Atherosclerosis. J Vasc Surg 63:453-458

26. Bucci M, Tana C, Giamberardino MA, Cipollone F (2016) Lp(a) and cardiovascular risk: Investigating the hidden side of the moon. Nutr Metab Cardiovasc Dis 26:980-986

27. Hopewell JC, Seedorf U, Farrall M, Parish S, Kyriakou T, Goel A, Hamsten A, Collins R, Watkins H, Clarke R, Consortium PROCARDIS (2014) Impact of lipoprotein(a) levels and apolipoprotein(a) isoform size on risk of coronary heart disease. J Intern Med 276:260-268

28. Langsted A, Kamstrup PR, Nordestgaard BG (2014) Lipoprotein(a): fasting and nonfasting levels, inflammation, and cardiovascular risk. Atherosclerosis 234:95-101

29. Spence JD, Koschinsky M (2012) Mechanisms of lipoprotein(a) pathogenicity: prothrombotic, proatherosclerotic, or both? Arterioscler Thromb Vasc Biol 32:1550-1551

30. Boden WE, Probstfield JL, Anderson T, Chaitman BR, DesvignesNickens P, Koprowicz K, McBride R, Teo K, AIM-HIGH Investigators (2011) Niacin in patients with low HDL cholesterol levels receiving intensive statin therapy. N Engl J Med 365:2255-2267

31. Santos RD, Raal FJ, Catapano AL, Witztum JL, SteinhagenThiessen E, Tsimikas S (2015) Mipomersen, an antisense oligonucleotide to apolipoprotein B-100, reduces lipoprotein(a) in various populations with hypercholesterolemia: results of 4 phase III trials. Arterioscler Thromb Vasc Biol 35:689-699

32. Stefanutti C, Morozzi C (2016) HyperLp(a) lipoproteinaemia: unmet need of diagnosis and treatment? Blood Transfus 14:408-412

33. Mellwig KP, Pulawski E, Horstkotte D, van Buuren F (2012) Lipid apheresis: oxidative stress, rheology, and vasodilatation. Clin Res Cardiol Suppl 7:45-49

34. Mellwig KP, van Buuren F, Schmidt HK, Wielepp P, Burchert W, Horstkotte D (2006) Improved coronary vasodilatatory capacity by H.E.L.P. apheresis: comparing initial and chronic treatment. Ther Apher Dial 10:510-517

35. van Buuren F, Kreickmann S, Horstkotte D, Kottmann T, Mellwig KP (2012) HELP apheresis in hypercholesterolemia and cardiovascular disease: efficacy and adverse events after 8,500 procedures. Clin Res Cardiol Suppl 7:24-30

36. von Dryander M, Fischer S, Passauer J, Müller G, Bornstein SR, Julius U (2013) Differences in the atherogenic risk of patients treated by lipoprotein apheresis according to their lipid pattern. Atheroscler Suppl 14:39-44

37. Poller WC, Dreger H, Morgera S, Berger A, Flessenkämper I, Enke-Melzer K (2015) Lipoprotein apheresis in patients with peripheral artery disease and hyperlipoproteinemia(a). Atheroscler Suppl 18:187-193 